\title{
Aestheticising Change: Simulations of Progress
}

\author{
BAILEY, Jocelyn ${ }^{\mathrm{a}} ;$ STORY, Chad ${ }^{\mathrm{b*}}$ \\ a University of Brighton \\ b York University \\ * cstory@yorku.ca \\ doi: 10.21606/dma.2017.291
}

\begin{abstract}
If, following Rancière, politics revolves around who has power to articulate the sensible', then designers, as aesthetic practitioners, must be caught up in questions of politics. This is particularly so when design practice becomes part of the way public sector actors negotiate, envision and catalyse change in relation to public 'problems'. However, this is also typically a form of design practice that eschews any talk of aesthetics - presenting as de-skilled, democratic and 'de-aestheticised', in a sense. By analysing and re-describing such design practice in aesthetic terms here illustrated with an example from practice - we provide an alternative characterisation to the more instrumental account of design as a reliable route to innovation for public sector managers. This opens up a different perspective on what such practices function to achieve, and what is at stake: an effacing of the political nature of design decisions, and an obscuring of the real work of change by the seductive techniques of simulation.
\end{abstract}

Keywords: design; public sector; aesthetics; politics

\section{Introduction}

It appears, at least according to mainstream media reports, that we are in an epic period of change. But what does all this change look like? How do we know when it is happening - and who benefits? To believe that one is experiencing change, or at the very least that change is possible, requires material evidence - to feel, see, touch and hear it. And so there is an aesthetic and material quality to change. We use the term 'aesthetic' here in its most general sense, to refer not simply to qualities of art or style (as aesthetic might often be interpreted when discussed in relation to design), but to those aspects of experience that manifest themselves to the senses, or as Rancière (2006) argues, "what presents itself to sense experience" (p.13).

Materializing change by embodying potential in artifactual form, and manipulating aesthetic experience, are defining features of design practice. Prototypes, for instance, have been called "figures of suspension and expectation" functioning as "traps' for the emergence of compossibility" (Jiménez, 2013, p.381). They serve as provisional markers of change by way of their precarious and 
often rudimentary character. These artifacts draw upon broader narratives of change inherited by the design profession; a historicity wherein the design professional has been heralded as the creative genius from which innovation, progress and, by extension, change is realized (Sparke, 1983; Kimbell, 2011; Suchman, 2011). It is from this privileged position - designer as catalyst - that the "aesthetics of change" are monitored, curated and produced to make change knowable. These aesthetics, as we argue, have less to do with appearance and style, but instead the manner in which controversial issues are rendered sensible (knowable) for public consideration.

Our focus here is specifically on the public sector, where design is increasingly proposed and mobilised as a catalyst for change (Mager, 2011; Julier, 2017). On a global scale, there are emerging fields of design that are bound up in the shaping of government policies, strategies, services, innovation, and change. This intensification of design activity has led to new practices derived from design being gradually absorbed and normalised by non-designers within government, often under the guise of public sector innovation (Windrum and Koch, 2008), policy design (Junginger, 2017), and service design (Buchanan, Junginger and Terrey, 2017). This is evidenced in the uptake of internal design labs in public sector contexts (cf. FutureGov, 2017; Public Policy Forum, 2013), a growing field of public discourse and debate principally managed, curated and facilitated by the design industry (Julier, 2017), research into public sector design best practices (Bason, 2014), and the proliferation of consultancies that specialize in design related services for government, such as Livework in the United Kingdom and Doblin in Canada.

Theorisations of these trends, situated within broader discourses of innovation, public sector renewal, and democratic participation, follow a distinct pattern: design is positioned as a problemsolving faculty, coming to the aid of the public sector at a time of crisis. This positioning of design as a means of introducing "new ways of working" in an effort to combat "complex problems" is strengthened by actors in academia and industry who actively make the case for design intervention. The notion of a new kind of design practice thus flows through an international discursive community of designers, researchers, civil servants and others. Our project here is to question this narrative by looking at these practices from a different - aesthetic - perspective, one which exposes the political dimensions of the work, and opens up a more nuanced discussion.

We examine the field through the lens of each author's localised engagement with it - both as practitioners and researchers - in Canada and the United Kingdom. We use an example from a local government change project to shed light on a wider field of practice, and demonstrate how the design profession carefully curates narratives of change in the public sector through the aesthetic choices made in the planning, enactment, and documentation of participatory design projects. We unpack the particular aesthetic modalities of what we have seen - design presenting as de-skilled, democratised, and in some ways 'de-aestheticised' - and discuss the function this might be serving: purporting to empower the bureaucrat while enrolling them as willing participants in change programmes, and presenting design practice as rational and logical in order to avoid the risks and complications of political entanglement. Drawing upon Jacques Rancière's (2006) concept of 'distribution of the sensible', we argue that an aesthetic of 'public sector change via design' has emerged that obscures the practicalities of political change - messy, relational and often affective work - in favour of what appears as change: a simulation of what design purports to deliver. full paper submissions for DRS2018 will be selected through a double-blind review process conducted by an international review panel.

\section{Standpoint and Methodology}

We have drawn out some distinct aesthetic modalities through a socio-material reading of practice. More specifically, this analysis examines how "materials (objects, tools and infrastructures)", "competencies (knowledge and embodied skills)", and "meanings (cultural conventions, expectations, and socially shared meanings)" (Shove, Pantzar, \& Watson, 2012, p. 23) are configured in specific design encounters, such as co-design workshops, to form 'proto-practices', or new ways of 
working and doing in situated contexts. Design objects, interactions, and dialogue between participants become texts that can be read and interpreted discursively. Our analysis focuses on meta discourses that arise in these encounters in order to understand how they contribute to, are predicated on, and respond to discourses of public sector design and innovation.

While this analysis is illustrated with one concrete example of public sector design, it is informed by our ongoing $\mathrm{PhD}$ research that examines the importation of design methods, tools, and approaches to work into public and democratic contexts, drawing upon a range of case examples, interviews, participant observation, and auto-ethnographic accounts in Canada and the United Kingdom. More specifically, we examine the political implications of public sector design - the production of subjects and subjectivities - and situate this analysis within a genealogy of design: namely a practice that is born out of, contingent upon, and at times, functions in opposition to industry.

\section{Aesthetics and Design}

Design is an aesthetic practice: both in terms of the decisions that are made through the process of giving form to objects and images, but also in terms of the kinds of experiences that design objects afford. And yet aesthetics in the context of design has historically been confined to discussions of beauty and taste, and more specifically, how objects are crafted to appeal to the eye. These accounts rely upon a philosophical and phenomenological tradition that enquires into the essential qualities of beauty that are manifest in art and literature, or as the work of Immanuel Kant explores judgements of taste. Design objects are difficult to assess according to this aesthetic approach because unlike art, they are also concerned with questions of function; design 'objects' (as in, the productions of design) must address practical human needs if they are to be deemed useful. Thus, the aesthetic quality of design objects is as much about capacity to fulfil a particular need as it is about appearance to the eye.

Perceptions of usefulness cannot be separated from appearance, as these qualities form part of the sensuous character of a designed object. Take for instance the term 'affordance' which is used in design to describe how the performative qualities of an object are rendered sensible to end users. During the process of design, the designer attempts to identify the wishes, aims, behaviours and skills of users. These things are instantiated in material form; the resulting artifacts are inscribed with actions, protocols and instructions for future use (Akrich, 1992). A chair, for instance, with its scooped bottom and straight back suggests by its aesthetic form that it is perfectly suited to accommodate a human body while in a seated position. The aesthetic of the chair, the manner in which it presents itself as sensible to the user, "mediates and conditions experience and our basic access to experience" (Folkmann, 2013, p. 26). The demonstrable aesthetic of the object "frames" the user's experience (i.e. calling out its presence as a chair) and affording particular courses of action (i.e. to sit). Aesthetic practices, therefore, delimit our experience of the world inasmuch as our very sense of what is knowable is made possible only through ongoing material attachments. Put simply, the world may become knowable when rendered sensible through material action.

\section{4. (Re)Distributing of the Sensible}

Jacques Rancière's concept 'distribution of the sensible' is a useful starting point to consider the interplay between politics and aesthetics. As he puts it, "politics revolves around what is seen and what can be said about it, around who has the ability to see and the talent to speak, around the properties of space and the possibilities of time" $(2006$, p.13). If phenomena remain unknowable, that is they are not rendered in some sense-able way, then they cannot be spoken of, thought about or acted upon. Rancière argues that social order itself is established through the distribution of the sensible, which polices common sense and what becomes unquestionable within society.

Distribution of the sensible is a useful concept for examining how privileged narratives of change are articulated and circulated because it draws attention to those who have the authority to legitimize narratives. Rancière's theory of aesthetics points to the political role designers play in managing a 
design process: selecting what and whom to include, or who can 'speak' within the process, deciding how the problem ought to be framed, and which issues ought to be made sensible - predominantly through form-giving. As consummate form-givers, designers, working with project stakeholders, render images of the future-in-the-present (cf. Yelavich and Caccavale, 2014), and as such, have a political stake in delimiting the terms of how change is understood, discussed and realized in the public sphere. This work is made possible by way of aesthetic practice, such as prototyping, storyboarding and role playing, that becomes material evidence of the kind of public sector change envisioned by design.

The aesthetic practices of participatory design within this setting in particular demand scrutiny: at first sight they may seem more inclusive and accessible than dominant bureaucratic aesthetic modalities, and this is ostensibly why they are employed. In which case, the question of what is included and what is left out becomes even more acute.

\section{Applying the Aesthetic Lens}

Gagliardi (2006) makes the case for an aesthetic reading of organisations, arguing that all organisations have an aesthetic, meaning a set of ways the organisation manifests itself to the senses. This is reflected in architecture, branding, communications materials, and other physical, sensible things that are the carriers of organisational culture more than ephemeral actions, thoughts or speeches:

Artifacts... are themselves ... primary cultural phenomena which influence corporate life from two distinct points of view: (a) artifacts make materially possible, help, hinder, or even prescribe organisational action; (b) more generally, artifacts influence our perception of reality, to the point of subtly shaping beliefs, norms and cultural values. ( $p$. 706)

This being so, the introduction and use of design practices into public sector organisations - which in general serve to introduce new and different artifacts - can be seen as an intervention in organisational culture and politics via a kind of aesthetic interference.

It seems, however, dominant design research and practice cultures are far from recognising this aspect of their own operations. Tonkinwise (2011) documents a concerted effort in "Design Thinking" to downplay the role of aesthetic judgment. He attributes this resistance to the perceived subjectivity of aesthetics: the managerial class considers aesthetics as "inherently subjective and/or cultural" and thus "foreground interpersonal politics" (p.536). Read historically, these actions sit within a broader history of consultant design which has tended toward a modernist ethic that eschews decoration and style for form and function: positioning design as a repeatable (rational) process for problem-solving, 'design as science' as opposed to 'design as art'. This derives from a widespread reliance on Herbert Simon's treatise as a means of legitimising both design research and practice, but this is not unproblematic, as Huppatz (2015) points out, "Much contemporary design research, in its pursuit of academic respectability, remains aligned to Simon's broader project, particularly in its definition of design as "scientific" problem solving" (p.29).

As Tonkinwise concludes, "this risks concealing the way in which designing is the designing in, with and of styles; styles that make possible existing and new forms of social practices" (p. 543). The emphasis on rational process (rather than subjective form-giving) has produced a distinctive visual language, intended to emphasize neoliberal value creation, creative know-how, and entrepreneurial optimism (Julier, 2017, p145). Journey maps, process diagrams, sticky notes: each of these artifacts, through their associations and affordances, dispel the notion of design as an expert practice of object-styling. Insistence that design thinking reject style, a kind of anti-aestheticisation, is predicated on a series of aesthetic judgments intended to improve the allure of design, not as subjective cultural product, but as change process, equally applicable in a variety of contexts, 
including the public sector. This is not an absence of aesthetics, it is a new and pervasive aesthetic idiom that requires critique.

\section{Designing Approaches to Homelessness Prevention in the UK}

To illustrate our analysis, we have selected an example of design practice deployed as public-sector change process - a project for the housing department of a UK local authority - which exhibits some of the typical aesthetic modalities in operation, and illustrates how design practice serves to render political issues sensible, or not, through careful aesthetic choices.

\subsection{The Brief}

The local authority in question commissioned a design consultancy (for whom one author was working) to help develop a homelessness prevention programme. This was to include early detection of those likely to be at risk of homelessness, early intervention and prevention strategies, and a culture change programme to support staff to transition to new ways of working. The brief was open-ended; the agency was simply asked to help the local authority work up a general strategy to be delivered over the following two years.

\subsection{The Design Response}

Working closely with managers in the housing service, and holding weekly workshops and conversations with the wider housing staff, the design team planned a three-month period of intense design work, following the double diamond process model (British Design Council, 2015).

In discovery, a homelessness prevention map and a set of personas was created with housing staff and using housing data, which sketched out a typology of people in different risk categories - 'not at risk', 'at risk', and 'in crisis' - and the 'triggers' and 'resilience factors' that might tip people one way or the other.

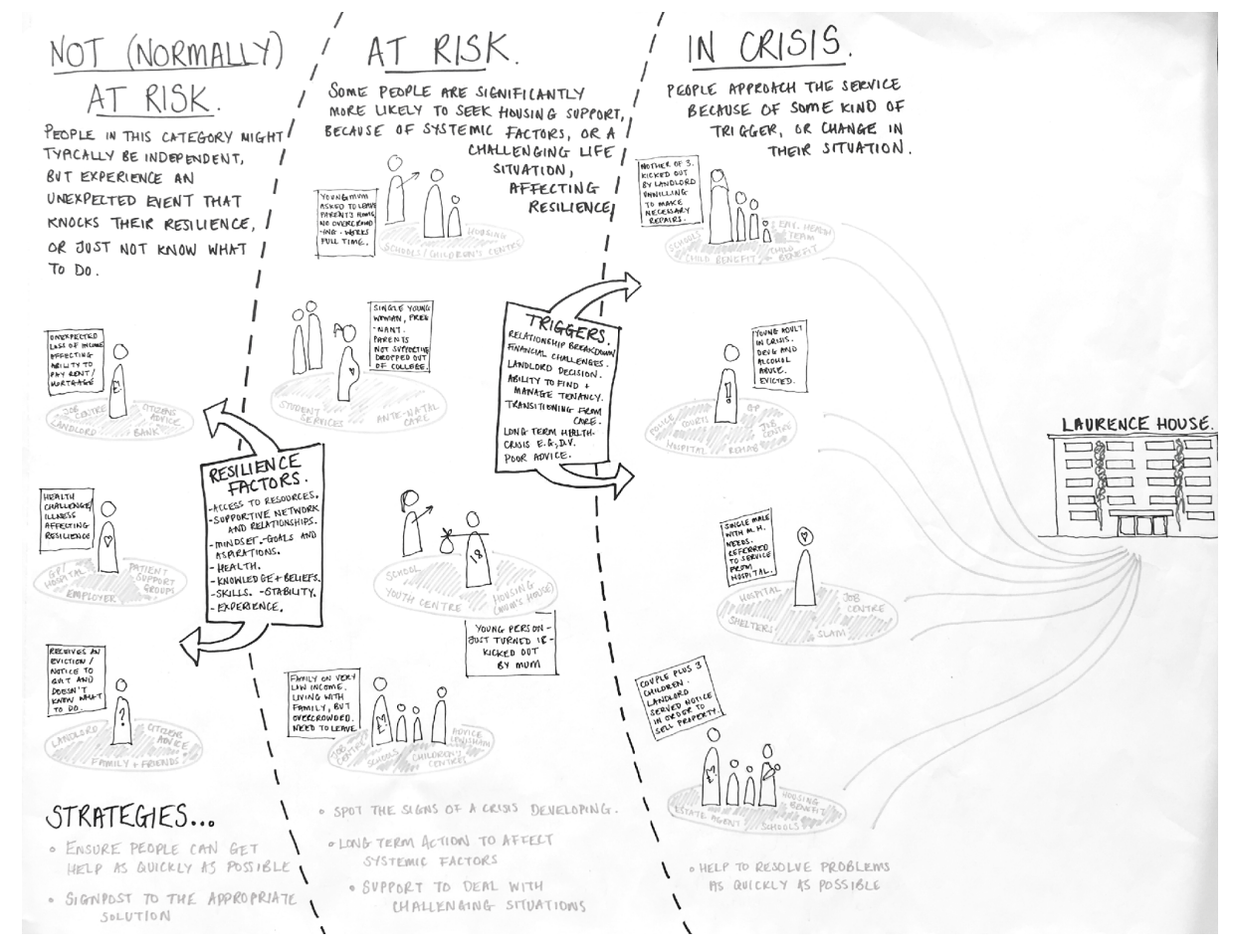

Figure 1: mapping people at risk of homelessness

In define, the project board (a mixture of team leaders across different parts of the housing service) used the persona stories to identify opportunities to intervene earlier in the journey towards homelessness - in some cases much earlier, for example in childhood. These were then regrouped into an 'opportunities matrix'. 


\begin{tabular}{|c|c|c|}
\hline Long term strategies & Medium term strategies & At the front door strategies \\
\hline \multicolumn{2}{|c|}{ Affecting the supply of affordable housing } & \\
\hline \multicolumn{3}{|c|}{ Managing difficult situations } \\
\hline \multicolumn{3}{|c|}{ Shifting perceptions and expectations } \\
\hline \multicolumn{3}{|c|}{ Equipping people to be independent } \\
\hline & \multicolumn{2}{|c|}{ Identifying problems before they become a crisis } \\
\hline & \multicolumn{2}{|c|}{ Making it easier for people to solve their own problems } \\
\hline & & Quick resolutions in a crisis \\
\hline
\end{tabular}

Figure 2: the prevention opportunities matrix (high level)

In develop, housing staff attended an ideas workshop, in which they were guided through collaborative creative activities and brainstormed new ways of responding to some of the opportunities.

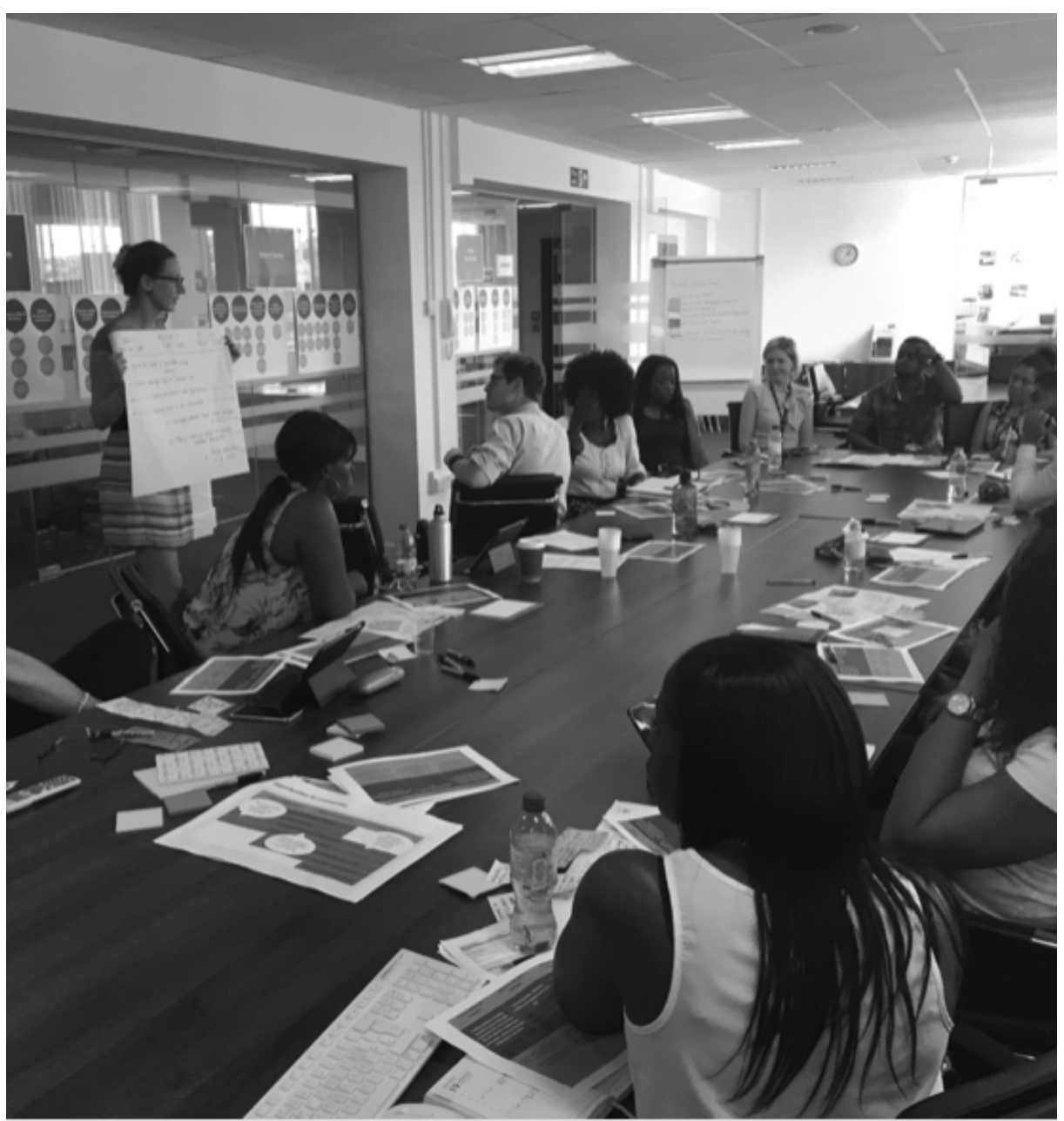

Figure 3: the ideas workshop with council staff

In deliver, some prevention ideas were selected, developed, visualised, and in one case actively prototyped: housing staff role played, and then live-tested, a new way of having more 'empathic and collaborative' conversations with clients. The agency then produced a report summarising the overall strategy, identifying key changes that would support the organisational shift to prevention, and making recommendations around culture change. 


\section{Analysis}

This example serves as a helpful reference point to discuss the aesthetic modalities at play in this design-led approach to envisioning change, where design is emphasised as process (the double diamond) and method (workshops and design activities) as much as outcome. Beyond the general observation that this kind of practice marks a distinct break or departure in aesthetic terms from 'normal' civil service practice - a symbolic aesthetic disruption - we have identified some recurring aesthetic features of the idiom, which set it apart from other design idioms, and which we have articulated as 'temporality', 'playfulness', and 'provisionality'.

\subsection{Temporality}

Time is a pronounced feature of public sector design practice: both in terms of the pace and structuring of work, and as part of the material of design.

Speed seems to be essential to the narrative around how to do this kind of design. It is reflected in the nomenclature - 'rapid' prototyping, lateral thinking 'sprints', hackdays and 'jams' - and infused into practice - starting, stopping and developing ideas quickly in workshops; producing design 'things' and project outputs within short spaces of time; doing rather than debating. This is perhaps the colonising influence of Silicon Valley-style working practices: 'lean', 'agile', etc. (Avle, Lindtner and Williams, 2017), where pace has come to be synonymous with creativity, but it also plays into a sense of urgency in the (currently austerity-riven UK) public sector about delivering innovation and ultimately savings. In contrast to the supposed inertia of the bureaucratic machine, design proposes itself as a light-footed and entrepreneurial catalyst of change. The aesthetic communicates the value of trying things out and 'failing fast', and demonstrates that moving at pace is possible.

Time is also the material we are working with, brought into view as a dimension of reality through (for example) constructing an individual's life history and projecting forward, developing service propositions as narratives that unfold over time, stripping away the messy non-linear complexity of life to highlight certain 'key' moments or issues in a trajectory. As a practice it introduces speculation as a valid form of data-gathering, thus proposing to make the future sense-able, knowable - and therefore manageable. It serves to bring subjects and their (past, present or future) capacities into range, manipulable as the material of public sector change.

\subsection{Playfulness}

Play is implied through both activities and materials. Light-hearted 'warm-ups' begin the process of aesthetic disruption through physically mixing people, or inviting different modes of expression. Idea generation activities are deliberately far-fetched, asking people to imagine 'what would happen if ...?', and to push beyond the bounds of normality. Workshops loosely follow the structure of a game or competition - there are rules and guidelines, permitted and non-permitted behaviours, silliness and laughter. The materials of the craft invite play in various ways: some are deliberately reminiscent of childhood (pipe cleaners, coloured card, balloons, Play-Doh, etc.); some suggest neutrality and universality - post-it notes, sharpies, newsprint - and downplay the need for draughtsmanship or skill; others suggest disposability and impermanence.

All of this playfulness performs multiple functions: it invites participation and lowers the barriers to action, symbolises a break from business as usual, permits creative thinking, engenders collaboration, and (hopefully) elicits goodwill from participants.

\subsection{Provisionality}

Provisionality is inherent to design process, and is perhaps the biggest point of difference when contrasted to 'normal' civil service practices as we have observed it through our ongoing research in this area. Provisionality is communicated both explicitly as part of the method: building iteration into the project plan, or holding a 'prototyping' phase. It is infused into micro-practices: the nature and 
quality of materials as noted above; constant representation and re-representation, making ideas sensible for dialogic purposes; leaving things on the walls and building up layers of work; working interactively, visibly taking and incorporating feedback. It is also produced and communicated through the performance of (co-)design practices: symbolically breaking away from traditional meeting formats, literally changing the layout of tables and chairs, sticking things to the walls, and creating a sense of creative clutter. All of this affords the possibility to re-distribute the sensible, or at the very least to temporarily rescript these environments as venues to intervene and disrupt how one ought to behave when in a public sector organisation.

Provisionality serves multiple ends. This work privileges material practice as a mode of expression that gives provisional ideas a form other than words, spreadsheets, and powerpoint slides; in other words, it makes change sensible in different ways. Provisionality is dialogic: it allows ideas to emerge and evolve. And it is persuasive. Unfinished design objects can hold great rhetorical power. In the homelessness example, acts of representation - perhaps because of their clarity of communication - gave confidence and certainty to the client. What the design team experienced as subjective, sometimes arbitrary, and often simply expedient decisions, took on a life and rationale of their own: as one option is made sensible, all other past potential options fade from view.

\section{Discussion}

Design practice cannot escape its aesthetic modalities, and an aesthetic reading of practice, such as we have attempted here, serves to demonstrate what is made knowable, what can be discussed and what can be acted upon within the scope of the design process; and also, we argue, what design, performatively, is functioning to do. Design activities police the nature and quality of action that is directed towards "changing existing situations into preferred ones" (Simon, 1996, p.111); they determine how, who and by what means change is to be realized.

We have proposed three dominant aesthetic modalities to this new design idiom, and noted some common aesthetic markers. What is clear here is a kind of de-emphasizing of style and expertise. The sheen, degree of polish and state of completion of the objects is replaced with another aesthetic that implies creativity and inclusivity. In what follows we speculate on the function this might be serving.

\section{1 (dis)Empowering Bureaucracy}

These practices are symbolically different to 'business as usual' - a way of performing the work of change that differs in pace, tone, detail, etc., and also functions as a visible marker of inclusivity and organisational willingness to innovate. They promise to empower the apolitical bureaucrat with a neutral and logical set of tools for innovation, with foresight, and insight into the subjective selves of citizens. Creativity is democratised - evident in the particular kind of naive design language (the opposite of, for example, an architect's drawing) that plays down the idea of expertise. The aesthetic suggests that anyone can (and should) do it. Or can they? In the homelessness example, despite performances of collective creativity, the ensuing ideas were not wildly different from the existing range of services, and had to be covertly supplemented by the design team. There's a sort of skillless design going on, where the ideas of the non-designers are overtly privileged, as though the appearance of a collaborative process, the democratisation of creativity, is more valuable than the actual ideas.

This begs the question of whether it is empowerment or distraction, innovation or anti-invention, grappling with politics or effacing them. In a time of political dysfunctionality, do we need more or less investment in the refinement of expertises of bureaucracy? As DiSalvo (2010) notes, "diverting attention away from the political by a focus on politics, i.e., a focus on the improving the mechanisms of governance, can endanger the practice of democracy because it draws us away from engaging in the contestation necessary for democracy" (p. 3).

\subsection{Consensus, Dissensus and Issue-Framing}


Provisionality and playfulness grants permission - to have unfinished ideas, to explore concepts that can be discarded, to 'try things out' - and thereby signifies the opening up of a space of potential contestation and agonism. However, in practice, there are limits drawn around the allowable forms of dissensus. These design practices "overwhelmingly gather at that end of the spectrum governed by the principle of consensus" (DiSalvo, 2010, p.1): they do not have forms for dealing with disagreement, dissent, and polemic. Issues that sit outside the problem framing are 'parked' rather than wrangled with. In keeping with 'managerial' styles of government that seek to achieve consensus through promotional rather than political tactics, these aesthetic modes tend to neutralise resistance (Fairclough 2000).

In the homelessness example, often throughout the project, but particularly acutely within the ideas workshop, certain problems were raised that were deemed 'out of scope'. In particular, the housing staff were quite united in their view that the causes of homelessness were political and structural, and therefore far beyond their remit to effect change: "It's not a local government problem - it's central government". There was always some discussion about this fundamental contradiction at the heart of the project (in their view) - sometimes this coalesced into unsanctioned discussion outside of the main agenda, and sometimes it came out through the more imaginative and playful activities that encouraged them to express their wildest hopes and ideas for change. But in later stages these ideas were easily weeded out as impractical, and thus remained, ultimately, unrepresented. In determinedly solution-seeking within the local authority remit, solutions have predictably been found, and they operate either on the machinery of local government, or the psychology and behavior of individuals. Ideas that address national politics, macro-economic conditions, and wider social norms, are absent. But the tactics and forms of design as deployed here have helped enroll staff as willing participants in this approved programme of change.

\subsection{Simulation and Change}

Simulation can be a useful and compelling step on the path to change. In our example, the act of role playing the new conversation held enough rhetorical power to spark action. A trial period of holding conversations with clients differently is underway, staff by their own admission have started seeing homelessness as one among many issues they might help with, and are experimenting with how they perform their roles and work.

The design objects (prototypes) produced here were simulacra of new situations, rather than the change itself. This is not a criticism of design - it is what design does. But there is a risk of misrepresentation - or misperception - of how much is actually being achieved in the design process. The sense of potential change afforded is powerful and attractive in the context of contemporary bureaucracy where public servants are frustrated and keen to find ways to empower themselves to create change. It is also attractive in the context of difficult public issues because it radically simplifies - reducing the challenge to a cluster of post-it notes or a tantalisingly clear service journey. People leave workshops with a sense of satisfaction. Something has been made. An idea has been realised; but only in the temporary reality of the workshop. There is a kind of virtualism to it: a prototype seems closer to a new situation than, for example, a white paper, even though it is not - and in some cases it might even hold less authority in legal terms.

Unlike other design fields, there is no clear account here of the journey from design to delivery from prototype to real change. In this way, this aesthetic of change risks obscuring the practicalities of the messy, relational and often affective work that is required.

\section{Conclusion}

If the dominant discourse around current emerging trends such as 'design for government/ public services/ policy' makes the case for such practice on the basis of increasing certainty about reaching the 'right' answer through a logical process (risk management around innovation and change), what we are drawing attention to here is an alternative characterisation of what design does and what it 
produces. Its particular aesthetic idiom promotes design as a desirable, neutral and inclusive set of practices, in a way that masks the other things it might be functioning to do: dismantling resistance and enrolling subjects, and - through the seductiveness of design objects and practices, the clarity of the simulation - obscuring the political realities of change in government, or indeed the messy reality of governed subjects. As designers, the de-aestheticisation helpfully allows us to pass ourselves off as rational modernists, thus avoiding the need for political entanglement. But imagining or simulating the change will not do the hard work of making it happen, and it must not be taken as such. Taking a design approach to public sector change processes - instead of providing a straightforward path to an inevitable answer (as it might be marketed) - requires design practitioners, and those working with them through a design process, to make constant decisions, judgements, choices etc. about what, exactly, is made 'sensible', and how. Far from being neutral and rational, design practice is subjective and political--and must be so.

\section{Acknowledgments}

The authors gratefully acknowledge the support of the UK Arts and Humanities Research Council/ Design Star Centre for Doctoral Training and York University Graduate Studies Fellowship.

\section{References}

Akrich, M. (1992). The de-scription of technical objects. In W. E. Bijker and J. Law (Eds.), Shaping technology/building society: studies in sociotechnical change (pp. 205-224). Cambridge, Mass: MIT Press.

Avle, Lindtner and Williams. (2017). How methods make designers. Proceedings of CHI 2017, May $06-11$. Denver, CO, USA. ACM. http://dx.doi.org/10.1145/3025453.3025864

Bason, C. (Ed.). (2014). Design for policy. Surrey: Gower Publishing Inc.

British Design Council. (2015). The design process: What is the double diamond? Retrieved from http://www.designcouncil.org.uk/news-opinion/design-process-what-double-diamond

Buchanan, C., Junginger, S., and Terrey, N. (2017). Service design in policy making. In D. Sangiorgi and A. Prendiville (Eds.), Designing for service: key issues and new directions. London; New York, NY: Bloomsbury Academic, an imprint of Bloomsbury Publishing Plc.

Corsín Jiménez, A. (2014). Introduction: the prototype: more than many and less than one. Journal of Cultural Economy, 7(4), 381-398. https://doi.org/10.1080/17530350.2013.858059

DiSalvo, C. (2010). Design, democracy and agonistic pluralism. In D. Durling, R. Bousbaci, L.L. Chen, P. Gauthier, T. Poldma, S. Roworth-Stokes, and E. Stolterman (Eds.), DRS 2010 Montreal Conference Proceedings (pp. 366-371). Montreal: DRS.

Fairclough, N. (2000). New Labour, new language. London: Routledge

Folkmann, M. N. (2013). The aesthetics of imagination in design. Cambridge, Mass: MIT Press.

Futuregov. (2017). Growing government innovation labs: an insider's guide. UNDP: http://www.eurasia.undp.org/content/rbec/en/home/librarypage/growing-government-innovation-labs-an-insider-s-guide.html accessed 30.10.2017

Gagliardi, P. (1999). Exploring the aesthetic side of organizational life. In S. Clegg and C. Hard (Eds.), Studying organization: theory and method (pp. 311-326). London: SAGE Publications Ltd. https://doi.org/10.4135/9781446218556.n12

Huppatz, D. (2015). Revisiting Herbert Simon's "Science of Design." Design Issues, 31(2), 29-40. https://doi.org/10.1162/DESI_a_00320 
Julier, G. (2017). Economies of design (1st edition). Thousand Oaks, CA: SAGE Publications.

Kimbell, L. (2011). Rethinking design thinking: part i. Design and Culture, 3(3), 285-306. https://doi.org/10.2752/175470811X13071166525216

Mager, B. (Ed.) (2016). Service design impact report: public sector. Service Design Network: Hundt Druck $\mathrm{GmbH}$, Germany.

Public Policy Forum. (2013). Change labs and government in Canada. Ottawa: Public Policy Forum.

Rancière, J. (2006). The politics of aesthetics: the distribution of the sensible. London; New York: Continuum.

Shove, E., Pantzar, M., \& Watson, M. (2012). The dynamics of social practice: Everyday life and how it changes. Sage: London.

Simon, H. A. (1996). The sciences of the artificial (3rd ed). Cambridge, Mass: MIT Press.

Sørensen, E. (2016). Enhancing policy innovation by redesigning representative democracy. Policy and Politics, 44(2), 155-170. https://doi.org/10.1332/030557315X14399997475941

Sparke, P. (1983). Consultant design: the history and practice of the designer in industry. London: Pembridge Press.

Suchman, L. (2011). Anthropological relocations and the limits of design. Annual Review of Anthropology, 40(1), 1-18. https://doi.org/10.1146/annurev.anthro.041608.105640

Tonkinwise, C. (2011). A taste for practices: Unrepressing style in design thinking. Design Studies, 32(6), 533545. https://doi.org/10.1016/j.destud.2011.07.001

Windrum, P., and Koch, P. M. (Eds.). (2008). Innovation in public sector services: entrepreneurship, creativity and management. Cheltenham, UK; Northampton, MA: Edward Elgar.

Yelavich, S., and Caccavale, E. (Eds.). (2014). Design as future-making. London; New York: Bloomsbury Academic.

About the Authors:

Jocelyn Bailey is a PhD Candidate at University of Brighton. Her research is developing a critique of the contemporary design for government phenomenon, based on her years working in UK public sector and political contexts in various roles.

Chad Story is a PhD Candidate at York University. As a service designer and researcher, he examines the socio-political implications of public sector design and innovation in Canada drawing linkages between political theory and design practice. 